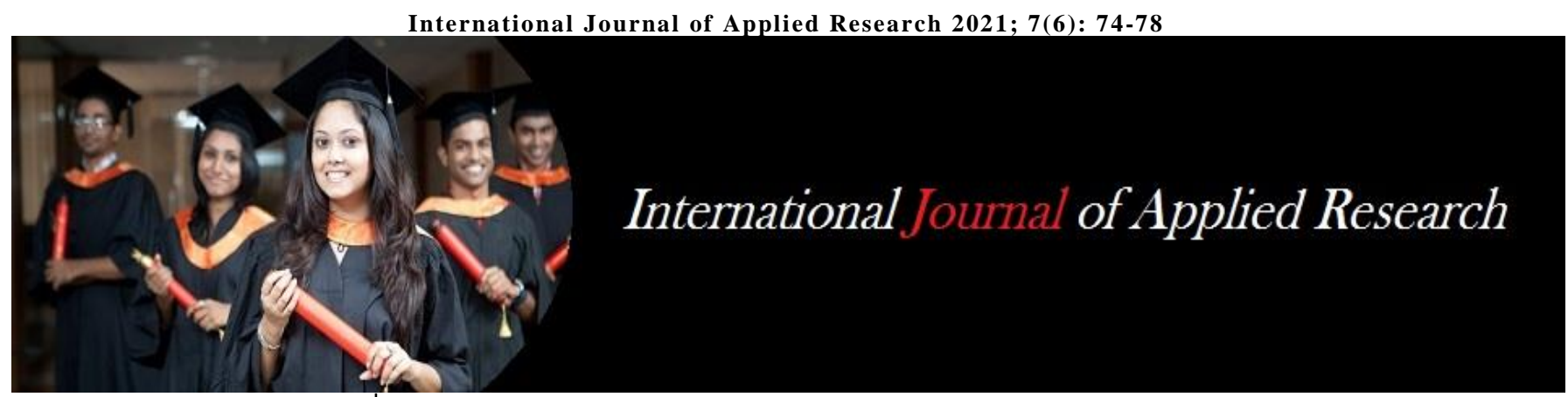

ISSN Print: 2394-7500 ISSN Online: 2394-5869 Impact Factor: 8.4 IJAR 2021; 7(6): 74-78 www.allresearchjournal.com Received: 05-04-2021 Accepted: 12-05-2021

\section{Dr. Shabnam Gurung} Assistant Professor, Department of Commerce, Ahmednagar College, Ahmednagar, Maharashtra, India
Corresponding Author: Dr. Shabnam Gurung Assistant Professor, Department of Commerce, Ahmednagar College, Ahmednagar, Maharashtra, India

\title{
Changing dynamics of work and workspaces during COVID-19 pandemic
}

\section{Dr. Shabnam Gurung}

DOI: https://doi.org/10.22271/allresearch.2021.v7.i6b.8634

\section{Abstract}

The past few months have been the most challenging for everyone. Making us realize and foster the power and vulnerabilities we carry as human beings. None of us prepared for navigating through a global crisis of this nature. People and organizations are swiftly adopting the new rules and creating a differentiator will be the winners of tomorrow. It is, therefore, imperative for us to recognize the changing needs of how we communicate and collaborate. These should circle back to the purpose of why we work, which is to make things, systems, and our lives easier and better.

Objective of the study: The objective of this article is to identify the changing dynamics of work, workspace and work force; also identified various work practices that the organizations' are trying adapt and reduce the cost on real estate. Reducing business travels due to the pandemic and getting used to various platforms to conduct business meetings has been on the rise. Pandemic may subside in the near future, organizations may make their workforce work remote and workstations may be very limited operationally. Infosys's strategies to adapt to new normal are also discussed.

Keywords: Work, workforce and workspaces

\section{Introduction}

The HR leaders must evaluate the lasting impact of corona virus pandemic not only on the future of work but also on the organizations operations and strategic goals, identify the priorities, examine to what degree these trends change pre and post COVID-19. Although it cannot be foreseen when all of this would be over, but whenever that happens commuting to office and interacting face-to-face with our co-workers may not be the same. $32 \%$ of organizations are replacing full-time employees with contingent workers as a cost-saving measure. Some companies are reportedly making a big move and considering permanent work from home for majority of their workforce. Such bold commitments are definitely making way for a futuristic way of working, and the fundamental aspects that are set to undergo transformation would be the $3 \mathrm{Ws}$-Work, Workforce and Workplace.

\section{Work}

Work will most likely be as it is right now with the 'future' already making its way to the 'present'. As we adapt to work from home, our reliance on email, chats, and videoconferencing is increasing, we are getting accustomed to interacting with companies virtually as well as depending on e-learning platforms over the traditional classroom trainings. This is leading to not only limited physical contact in response to the COVID-19 pandemic but also shaping the way work works. As employees' work lives have changed, so have the companies themselves. We can experience how online food delivery platforms jumped the bandwagon to make essential services and groceries available to us as we sit in the comfort of our home.

\section{Retailers}

Will need to rethink their business strategy and focus more on online delivery of products as the online shoppers have increased manifold, even if they maintain a brick-and-mortar store. This would mean a strengthened logistics and delivery system, less staff in-store and more gig workers to handle surges in online shopping demand. 


\section{Banking and financial services}

We can see how digital way of interaction is becoming the new normal as artificial intelligence and machine learning frontends to automate several processes and customers getting comfortable with online and mobile banking. Financial institutions will have to relook at their infrastructure that can support both digital and physical services efficiently with their manpower deployed to work from anywhere.

\section{Hospitals and healthcare}

Service providers are implementing virtual consultations that can be done through audio and video conferencing tools -giving rise to tele-health. And as we move towards the future of work, doctors and patients will be able to connect virtually over collaboration platforms instead of an inperson visit.

\section{Education sector}

Education sector has also undergone a huge transformation as the outbreak forced schools and universities to shut down. There has been a distinctive rise of e-Learning where children are being taught remotely and on digital platforms. Integration of technology with education will get accelerated and online education will become an integral component of school education creating a hybrid model with significant benefits. COVID-19 has almost impacted every sector and transition into a world of automation and brought radical change in the way we work. This would certainly not mean job destruction but job augmentation wherein the tasks performed by humans are most likely to shift to non-routine, more complex and innovative.

\section{Workforce}

Workers across the globe have been affected by lockdown in several ways. While for those in white-collar jobs, it has meant remote work; for several service/blue-collar workers, it has provided a peek into the future where machines may replace humans especially as enterprises consider automation; and for gig workers, there is a struggle these days. However, several companies across sectors such as automotive, media to business process management will explore areas that can be equipped with remote working models using freelancers and gig workers on a continued basis. There will be reluctance to add full-time roles when they could add flexible roles instead. Enterprises will also focus on engaging people with the right blend of expertise and experience to achieve their goals while enabling new ways of working while enhancing virtual work support systems. Continuously up Skilling is needed to address the talent shortages.

\section{Online meetings}

Pandemic has also shown that we do not need to fly to other cities or countries for business reviews. These meetings can be as effective when done through videoconferencing platforms. This would not only save company's cost but also reduce stress of travelling, save time and increase efficiency of the employees. However,

On the flip side, as working remote is increasing, humans being social animals, would miss the connecting with their peers and colleagues. While working from home, they may also feel like they never leave work, which can ultimately impact productivity. Hence, leadership teams will have the responsibility to address such pitfalls and beat the collaboration, productivity, and emotional disadvantages that can arise.

\section{Workplace}

As the work gets supported by an ecosystem of virtual resources; the organizations are certainly going to leapfrog into a new mode of work that will be the work to be done and not the place. Technology is going to play a pivotal role in transforming the workplaces-which will be a blend of the physical and virtual experiences. As enterprises consider to significantly reducing the number of employees working from office, they will not only save cost on real estate but also will have to transform work floors in a way that social distancing can be maintained. This could not only mean DE cluttering the office space but also doing away with the collaboration workspace for employees. The cramped cubicles build make way for spaced out workspaces. Coworking spaces which work on the concept of shared desks would lead to more segregated and private places. For instance, a meeting room that would normally fit eight individuals might now only hold seats for four. "It's critical for business leaders to understand that large-scale shifts are changing how people work and how business gets done," says Brian Kropp, distinguished Vice President, and Gartner. "HR leaders who respond effectively can ensure their organizations stand out from competitors."

\section{Future of work trends}

COVID-19 has forced the pendulum of a long-observed pattern to one extreme. Of the nine Future of Work trends, some represent accelerations of existing shifts; others are new impacts not previously discussed.

\section{Increase in remote working}

A recent Gartner poll showed that $48 \%$ of employees will likely work remotely at least part of the time after COVID19 versus $30 \%$ before the pandemic. As organizations shift to more remote work operations, explore the critical competencies employees will need to collaborate digitally, and be prepared to adjust employee experience strategies. Consider whether and how to shift performance goal-setting and employee evaluations for a remote context.

\section{Expanded data collection}

Gartner analysis shows that $16 \%$ of employers are using technologies more frequently to monitor their employees through methods such as virtual clocking in and out, tracking work computer usage, and monitoring employee emails or internal communications/chat. While some companies track productivity, others monitor employee engagement and well-being to better understand employee experience.

\section{Contingent worker expansion}

The economic uncertainty of the pandemic has caused many workers to lose their jobs and exposed others for the first time to nonstandard work models. Many organizations responded to the pandemic's economic impact by reducing their contractor budgets, but there has since been a shift. Gartner analysis shows that organizations will continue to expand their use of contingent workers to maintain more flexibility in workforce management post-COVID-19, and will consider introducing other job models they have seen 
during the pandemic, such as talent sharing and $80 \%$ pay for $80 \%$ work.

\section{Expanded employer role as social safety net}

The pandemic has increased the trend of employers playing an expanded role in their employees', financial, physical and mental well-being. Support includes enhanced sick leave, financial assistance, adjusted hours of operation and child care provisions. Some organizations supported the community by, for instance, shifting operations to manufacturing goods or providing services to help combat the pandemic and offering community relief funds and free community services.

\section{Separation of critical skills and roles}

Before COVID-19, critical roles were viewed as roles with critical skills, or the capabilities an organization needed to meet its strategic goals. Employers are realizing that there is another category of critical roles - roles that are critical to the success of essential workflows. To build the workforce, focus on skills needed to drive the organization's competitive advantage post - pandemic. Encourage employees to develop critical skills that potentially open up multiple opportunities for their career development, rather than preparing for a specific next role.

\section{Humanization of employees}

While some organizations have recognized the humanitarian crisis of the pandemic and prioritized the well-being of employees as people over employees as workers, others have pushed employees to work in conditions that are high risk with little support - treating them as workers first and people second.

\section{Emergence of new top-tier employers}

Prior to COVID-19, organizations were already facing increased employee demands for transparency. For example, advise CEOs and executive leaders on decisions regarding executive pay cuts and make sure financial impacts are absorbed by executives versus the broader employee base. Progressive organizations communicate openly and frequently to show how they are supporting employees despite the implementation of cost-saving measures. Where feasible, look for opportunities to arrange talent-sharing partnerships with other organizations to relocate employees displaced from their jobs by COVID-19.

\section{Transition from designing for efficiency to designing for resilience}

A 2019 Gartner organization design survey found that $55 \%$ of organizational redesigns were focused on streamlining roles, supply chains and workflows to increase efficiency. While this approach captured efficiencies, it also created fragilities, as systems have no flexibility to respond to disruptions. Resilient organizations were better able to respond - correct course quickly with change. To build a more responsive organization, design roles and structures around outcomes to increase agility and flexibility and formalize how processes can flex.

\section{Increase in organization complexity}

After the global financial crisis, global M\&A activity accelerated, and many companies were nationalized to avoid failure. As the pandemic subsides, there will be a similar acceleration of M\&A and nationalization of companies. Companies will focus on expanding their geographic diversification and investment in secondary markets to mitigate and manage risk in times of disruption. This rise in complexity of size and organizational management will create challenges for leaders as operating models evolve.

\section{How the workplace changed in early 2020}

A study conducted in 2018 predicted that remote work would equal or surpass fixed office work by 2025 . With the outbreak of COVID-19 in early 2020, the future of work arrived much sooner than anyone anticipated. Research firm Gallup released data in April 2020 showing that $63 \%$ of US employees worked from home due to corona virus concerns, and $91 \%$ of teams in Asia Pacific implemented work-fromhome arrangements since the outbreak. This sudden shift to remote work has introduced new and profound issues for both employers and employees as the virus necessitated that organizations prioritize safety over preparedness.

\section{Research from the Society for Human Resource Management (SHRM) found \\ - $71 \%$ of employers struggled to adjust to remote work. \\ - $65 \%$ of employers said maintaining employee morale and well-being has been a challenge. \\ - One-third faced difficulties with company culture.}

Virtual workplaces: Jobs that don't require employees to work on site may see a big turn toward remote work. Manufacturing, distribution, healthcare and service $=$ related industries still need the majority of their employees to commute to the workplace for the business to operate; however, jobs outside of these industries may go fully remote or have a much more significant percentage of employees working remotely.

Distributed offices: With more employees working remotely, organizations may open smaller regional hubs or provide remote workers with access to local co working spaces rather than have the majority of their workforce commute to one central office.

Online meetings: As companies continue to cut costs and balance their budgets, many experts believe business travel will be the thing of the past. "There are a few things, like business trips, that I doubt will ever go back," says Bill Gates, cofounder of Microsoft. "It's simply a measure of necessity and risk." It is a cost-effective and efficient method for conducting business and communicating with people all over the world.

The end of open-floor plans: Open office floor plan were popularized in the 1980s as a way to lower real estate costs, break down barriers between employees and managers and increase team collaboration. But if viruses such as COVID19 become more commonplace, it may be the end of openfloor plans and a move toward more private workspaces.

\section{Work from anywhere}

According to a recent study by Cushman \& Wakefield, a global commercial real estate services firm, $50 \%$ of the workforce will likely work across a "Total Workplace Ecosystem" - balancing working from the office, home and other places. 


\section{"Work from anywhere" - 5 tools for the future workplace}

1. Video conferencing: Life size - The Life size gives you an easy way to start a video chat, join a meeting or schedule a video conference call right from your PC, Mac, tablet or smartphone. This means that remote team members working from home, coffee shops, co-worker centers and on the go can all easily connect to a video call and have the same user experience as their in-office colleague.

2. Team chat: Microsoft Teams - is one of the most popular messaging apps and an exceptional tool for persistent collaboration and document sharing within the Office 365 platform. Employees can send one-on-one or group instant messages to their coworkers from any laptop or smart device.

3. Project management: Asana - is a popular web and mobile application designed to help distributed teams organize, track and manage their work. One of the best things about Asana is its simple and easy-to-use interface.

4. IT enablement: Okta - Okta is an access-management platform that secures a company's critical resources and provides a single sign-on solution for employees. With Okta, IT can manage employees' access to any application or device, regardless of their location.

5. File management and sharing: Google Docs - As part of the G Suite apps, Google Docs, let you create and work on documents with people inside and outside your organization and see live edits as others type and communicate through a built-in chat feature.

\section{Working dynamics of Infosys}

Infosys is a global leader in next-generation digital services and consulting, enable clients in 46 countries to navigate their digital transformation. With nearly four decades of experience in managing the systems and workings of global enterprises, Infosys expertly steer clients through their digital journey by enabling the enterprise with an AIpowered core that helps prioritize the execution of change. It also empowers the business with agile digital at scale to deliver unprecedented levels of performance and customer delight. Always-on learning agenda drives their continuous improvement through building and transferring digital skills, expertise, and ideas from its innovation ecosystem.

\section{Infosys is making every effort to tackle the turbulence to manage the impact of the crisis by \\ - Prioritizing Employees \\ - Serving and Supporting Clients \\ - Empathy for Community \\ - Focus on the Future \\ - Being Resilient}

\section{Infosys's efforts to manage the situation}

Infosys has well-defined disaster recovery and business continuity plans at various levels. In the light of the rapid spread of corona virus, it is constantly monitoring the situation, following government directives and ensuring regular communication with our employees across the world. Several measures -- including increased precautions at their facilities, travel advisories, remote working where feasible, and a dedicated helpdesk to ensure employee safety and business continuity.

\section{Infosys' business continuity plan}

Disaster recovery and business continuity plans function at the corporate, functional, location and account levels. Infosys also has a detailed pandemics response plan, which is based on WHO recommendations. These plans have been previously tested and bettered over decades, and guide us as we deal with unusual situations, such as the one we are faced with currently. The pandemics response plan, along with the corporate disaster recovery and business continuity plans are now being executed across Infosys locations. These plans enable a diverse set of strategies like remote working, work transfer (to offshore/onshore), and relocation of critical projects and resources, as required.

\section{Client services}

Infosys is taking multiple steps to ensure that, even as we deal with this unprecedented situation, we deliver on our key client deliverables, while following local government advisories and directives, and ensuring the safety of our employees and communities.

\section{Ensuring critical services do not get impacted}

Infosys remains committed to meeting its client deliverable mandates and ensuring that their critical client services do not get impacted. They are working every day to ensure that there is no disruption to any of our clients' critical operations and communicating regularly with clients in case they foresee any unavoidable disruptions.

\section{Keeping its employees safe}

Infosys had advised all its employees to work from home wherever possible, where work from home is not possible, extensive measures are taken to ensure the safety of its employees. Increased sanitization of all their office premises, removal of biometric scanners, installation of thermal scanners, daily communication updates, restricted movements in common areas, closure of recreational facilities and avoiding large gatherings. Dedicated helpline for the employees, and ensured that medical centers are available in every campus, with access to an ambulance.

\section{Travel advisories for employees and other stakeholders}

All non-essential travel, domestic as well as international travels were restricted to reduce the risk. It had also sent travel advisories to all employees to ensure their travel is as per the guidelines of the local government. All employees who had travel history to any international destinations or have come in contact with anyone had been asked to selfdeclare it to the company and follow the necessary quarantine protocols mandated by the local government authorities.

\section{Functioning of Infosys offices across the world}

Infosys offices across the world are following the local government directives, and based on the advisories determining if offices can be operational. Encouraging employees to work from home.

\section{Conclusion}

The workplace of the future is no longer a single location but a collaborative environment enhanced by technology 
that enables employees to work from wherever they are most comfortable and productive. This means designing workplaces around flexible work arrangements where employees can come and go from the office based on preference and as project work dictates. The workplace of the future is flexible, mobile and connected.

\section{References}

1. Admin, Microsoft \& OneFlow Leverage the Efficient Coding Principle to Design Unsupervised DNN Structure-Learning That Outperforms HumanDesigned, Cloud Hosting TV 2021. Retrieved on 06/06/2021 from https://www.cloudhosting.tv/category/deep-mind

2. Admin, New Ways of Working in Technology Revolution, 9 future of work trend post-COVID, 19, Mobility Global 2020. Retrieved on 21/05/2021 from https://blog.mobilityglobal.net/uncategorized/9-futureof-work-trends-post-COVID-19/

3. Anita Chabaria. How to engage alternative workforce during business challenges, Super Set Employee Relations 2020. Retrieved on 04/06/2021 from https://www.peoplematters.in/blog/employeerelations/how-to-engage-alternative-workforce-duringbusiness-challenges-26594

4. Brian Kropp, Gartner. 9 Future of Work Trends PostCOVID-19, HR \& Digital Trends 2020. Retrieved on 22/05/2021 from https://www.hrdigitaltrends.com/story/14484/9-futurework-trends-post-COVID-19

5. Brian Lassiter S. Leading Forward: Nine Emerging Trends in a Post-Pandemic World-July 2020, Pen sights -Performance. Excellence. Network 2020. Retrieved on 04/05/2021 from

https://www.performanceexcellencenetwork.org/pensig hts/leading-forward-nine-emerging-trends-in-a-postpandemic-world-july-2020/

6. COVID-19 Diary: The Perfect Recipe for Success in Technology and E-commerce Space Dustin Smith, What Will Future Workplaces Look Like After 2020? Lifesize 2020. Retrieved on 02/05/2021 from https://www.lifesize.com/en/blog/future-workplaces/

7. Editorial Desk. Future of work in Indian Post-COVID, Agency Reporter 2020. Retrieved on (07/04/2021) from https://www.agencyreporter.com/future-of-work-inindia-post-COVID/

8. Executive Forums. Introduction to the new work concept, Back to the office-Now what? Growth 2021. Retrieved on 10/05/2021 from https://executiveforums.com/back-to-the-office/

9. Kishtofore Brookes J. Ford offering work-from-home option to 30,000 employees, CBS News 2021. Retrieved on 05/06/2021 from https://www.cbsnews.com/news/ford-telecommuteremote-work-30000-working-from-home/

10. Mary Baker. 9 Future of work trends-COVID-19, Smartner with Gartner 2020. Retrieved on 09/05/2021 from https://www.gartner.com/smarterwithgartner/9future-of-work-trends-post-COVID-19/

11. Mark Helmod. Introduction to the new work concept, New work Transformation and Visual Leadership 2021. Retrieved on 08/05/2021 from https://www.ncbi.nlm.nih.gov/pmc/articles/PMC79810 00/
12. Managing Fears and Anxiety around the Coronavirus (COVID-19), Mental and Physical Wellbeing, Harvard College. Retrieved on 08/05/2021 from https://dso.college.harvard.edu/mental-and-physicalwellbeing

13. Pradeep Chakrawati. AI, RPA and Internet of Things going to redefine workplace: Harnath Babu, KPMG India, Data Quest 2020. Retrieved on 28/05/2021 from https://www.dqindia.com/ai-rpa-internet-things-goingredefine-workplace-harnath-babu-kpmg-india/

14. Parul Singh. Future of work in Indian Post-COVID, Linked In 2021. Retrieved on 29/05/2021 from Future of Work In India Post-COVID. (linkedin.com)

15. PTI. $60 \%$ companies looking to hire talent for new positions this year: Survey, ETCIO.com, from the economics times 2021. Retrieved on 09/06/2021 from https://cio.economictimes.indiatimes.com/news/corpora te-news/60-companies-looking-to-hire-talent-for-newpositions-this-year-survey/83361112

16. Salil Parikh. Ensuring Employee Safety and Building Business Resilience in the time of COVID-19, Infosys. Retrieved on 04/06/2021 from https://www.infosys.com/newsroom/features/2020/CO VID-19-update.html

17. Sarah Talbot, Marivic Espino, Ngozi Angela Ogwa, Benefits from new working practices, Keeping all team members visible and included and discover more. Hybrid working: New normal 2021. Retrieved on 06/06/2021 from

https://www.grantthornton.global/en/insights/articles/H ybrid-working-the-new-normal/

18. The Future of workplace is here. Woubu 2020. Retrieved on 06/06/2021 from https://wowbii.com/blog/the-future-workplace-is-here/

19. Technology for you. 9 Future of Work Trends PostCOVID-19, Technology for you 2020. Retrieved On 07/04/2021 from https://www.technologyforyou.org/9future-of-work-trends-post-COVID-19/

20. 10 Way to improve work efficiency - Be more productive at work and see what you're capable of Accomplishing, Tony Robbins. Retrieved on 02/06/2021 from

https://www.tonyrobbins.com/business/improve-workefficiency/\#mm-11 